\title{
The Atomic Level Journey from Aqueous Polyoxometalate to Metal Oxide
}

Yu Hou, Dylan B. Fast, Rose E. Ruther, Jenn M. Amador, Lauren B. Fullmer, Shawn R. Decker, Lev N. Zakharov, Michelle Dolgos* and May Nyman*

Center for Sustainable Materials Chemistry and Oregon State University, Department of Chemistry Corvallis, OR 97730

Contact:

Michelle Dolgos: Oregon State University, Department of Chemistry, Corvallis, OR 97330.

Michelle.Dolgos@oregonstate.edu, 1-541-737-9529.

May Nyman: Oregon State University, Department of Chemistry, Corvallis, OR 97330.

May.Nyman@oregonstate.edu, 1-541-737-1116. 


\begin{abstract}
Aqueous precursors tailored for the deposition of thin film materials are desirable for sustainable, simple, low energy production of advanced materials. Yet the simple practice of using aqueous precursors is complicated by the multitude of interactions that occur between ions and water during dehydration. Here we use lithium polyoxoniobate salts to investigate the fundamental interactions in the transition from precursor cluster to oxide film. Small-angle X-ray scattering of solutions, total X-ray scattering of intermediate gels, and morphological and structural characterization of the lithium niobate thin films reveal the atomic level transitions between these states. The studies show that 1) Lithium- $\left[\mathrm{H}_{2} \mathrm{Nb}_{6} \mathrm{O}_{19}\right]^{6-}$ has drastically different solution behaviour than lithium- $\left[\mathrm{Nb}_{6} \mathrm{O}_{19}\right]^{8-}$, linked to the precursor salt structure 2) in both compositions, the intermediate gel preserves the polyoxoniobate clusters and show similar local order and 3) the morphology and phases of deposited films reflect the ions behaviour throughout the journey from cluster solution to metal oxide.
\end{abstract}

\title{
1. Introduction
}

Aqueous precursor chemistries for functional metal oxide coatings are generating considerable excitement with the goal of sustainable, green processes for advanced technology materials ${ }^{1-4}$. While there are disparate examples of thin film coatings grown from aqueous cluster precursor solutions, detailed studies of the crucial chemical and physical states of the process, and the sequential transitions between these states has not been studied. Here we investigate the transition of aqueous lithium polyoxoniobate clusters to lithium niobate thin films as a benchmark study to delineate important features of the processes that may be universal in analogous aqueous cluster precursor chemistries.

Effective metal-oxo cluster precursors possess some degree of connectivity to the film ions, which decreases the energetic barrier for self-assembly and crystallization of the coating material; and they contain minimal species that would be considered impurities in the film, such as organic ligands or charge-balancing ions. Moreover, these aqueous cluster chemistries provide superior control over composition and morphology compared to precursor chemistries of simple ions or small molecules. ${ }^{5-8}$ Additionally, they have produced nanocomposites that could not be obtained otherwise. ${ }^{9-12}$ The fundamental steps of growing thin film materials from aqueous cluster precursors are illustrated generically in figure 1.

Alkali niobate and tantalate thin films are important in advanced technologies ${ }^{13-19}$ and serve as an excellent case study for understanding the direct influence of aqueous precursor chemistry on thin film growth. These chemical systems are of particular interest to the current study because the polyoxometalate Lindqvist ion $\left[\mathrm{M}_{6} \mathrm{O}_{19}\right]^{8-}(\mathrm{M}=\mathrm{Nb}, \mathrm{Ta})$ can be made as a salt of any alkali $(\mathrm{Li}, \mathrm{Na}, \mathrm{K}, \mathrm{Rb}$ and Cs) with excellent water-solubility. ${ }^{20-22}$ Therefore, the unique situation is exploited in which the 
aqueous cluster counterion is also an integral part of the film chemistry. Although the alkali Lindqvist ion salts have been utilized as precursors for alkali niobate and alkali tantalate powders, ${ }^{23-29}$ they surprisingly have not been used to grow films from solution.

Here we specifically address the $\mathrm{Li}^{+}-\left[\mathrm{Nb}_{6} \mathrm{O}_{19}\right]^{8-}$ precursor chemistry for lithium niobate films. In 2007, Ono and Hirano ${ }^{30}$ reported using alkoxide-derived, water-soluble Li-Nb-O-OH and Li-K-Nb-O-OH precursors for solution deposition of $\mathrm{LiNbO}_{3}$. While these solutions may have contained some derivative of the Lindqvist ion salts, they were not described as such, nor were details about their structure or solution state reported. We present herein two paths from aqueous cluster precursor solution, to deposited amorphous gel, to metal oxide film, using $\mathrm{Li}_{8}\left[\mathrm{Nb}_{6} \mathrm{O}_{19}\right] \cdot \mathrm{xH}_{2} \mathrm{O}$ and $\mathrm{Li}_{6}\left[\mathrm{H}_{2} \mathrm{Nb}_{6} \mathrm{O}_{19}\right] \times \mathrm{xH}_{2} \mathrm{O}$ precursors, respectively. Major characterization methods included small angle X-ray scattering (SAXS) of aqueous precursor solutions; and total X-ray scattering of the intermediate gels from the room temperature amorphous state up to the crystalline state. On a rudimentary level, composition was expected to be the most important controlling factor of the transition from precursor to thin film coating. However we've learned through this study that acid-base and ion-association chemistries of the aqueous and gel systems also significantly affect the key processes in this atom-level journey.

\section{Experimental}

\subsection{Preparation of Lithium hexaniobate}

$\mathbf{L i}_{8}\left[\mathbf{N b}_{6} \mathbf{O}_{19}\right] \cdot \mathbf{1 5 . 5} \mathrm{H}_{2} \mathbf{O}$ (Li8). Lithium hexaniobate, $\mathrm{Li}_{8}\left[\mathrm{Nb}_{6} \mathrm{O}_{19}\right] \cdot 15.5 \mathrm{H}_{2} \mathrm{O}$ (FW 1169.61), was synthesized by a method similar to that which we reported prior, which is essentially an ion-exchange of $\mathrm{K}^{+}$for $\mathrm{Li}^{+}{ }^{21}$ Briefly, 5 grams of $\mathrm{K}_{8}\left[\mathrm{Nb}_{6} \mathrm{O}_{19}\right] \cdot \mathrm{xH}_{2} \mathrm{O}$ (synthesis reported prior) ${ }^{22}$, which is highly soluble, is dissolved in a minimal amount of water. One liter of $1 \mathrm{M} \mathrm{LiOH}$ solution is prepared in a large beaker. While stirring, the highly concentrated $\mathrm{K}_{8}\left[\mathrm{Nb}_{6} \mathrm{O}_{19}\right] \cdot \mathrm{xH}_{2} \mathrm{O}$ solution is added rapidly to the $\mathrm{LiOH}$ solution via pipette. Upon halting the stirring; within a minute, the solution begins to cloud as microcrystals of less soluble lithium hexaniobate grow. The beaker is left for two days to allow full crystallization and settling. The crystals are collected by decanting the clear solution, centrifugation of the collected crystals and some mother liquor, and washing with methanol to rid of excess lithium and potassium hydroxide. Energy Dispersive Spectroscopy coupled with Scanning Electron Microscopy was used to confirm there was no $\mathrm{K}^{+}$present in the prepared salt. If potassium is detected, is recrystallized from $1 \mathrm{M} \mathrm{LiOH}$ solution again, and usually a second crystallization will rid of all $\mathrm{K}^{+}$. Compositional analysis (wt\%): theoretical (experimental) $\mathrm{Nb}$ : 46.6(48.1), Li: 4.69(4.68) A typical solution prepared with Li8 had a pH of 12.0. Li8 crystallizes as suitable size and quality for single-crystal X-ray diffraction. A crystal was selected for single-crystal analysis; see supporting information. 
$\mathbf{L i}_{6}\left[\mathbf{H}_{2} \mathbf{N b}_{6} \mathbf{O}_{19}\right] \cdot 14 \mathrm{H}_{2} \mathrm{O}$ (Li6). (FW 1155.73) An aqueous solution of $0.2 \mathrm{~g} \mathrm{Li}_{8}\left[\mathrm{H}_{2} \mathrm{Nb}_{6} \mathrm{O}_{19}\right] \cdot 14 \mathrm{H}_{2} \mathrm{O}$ in $40 \mathrm{ml}$ $\mathrm{H}_{2} \mathrm{O}$ was acidified from $\mathrm{pH} 11.8$ to 11.0 by $0.1 \mathrm{M} \mathrm{HCl}$. Then, $120 \mathrm{ml}$ isopropanol was added into that solution to form a cloudy solution which was centrifuged for $1 \mathrm{~h}$. The obtained solid was collected, washed by isopropanol for three times and air dried at room temperature. Yield: 0.16g. Compositional analysis (wt\%): theoretical (experimental) Nb: 48.3(47.7), Li: 3.58(3.75) A typical solution prepared with Li6 had a pH of 10.9. Li6 never produces crystals sufficient for single-crystal analysis; rather they were characterized by powder diffraction, see SI. This is pertinent to later discussion on film morphology.

\subsection{Aqueous cluster solution studies}

Small-angle X-ray scattering data were collected on an Anton Paar SAXSess instrument with $\mathrm{Cu}-\mathrm{K} \alpha$ radiation and slit collimation in the q-range of $\sim 0.1-7 \mathrm{~nm}^{-1}$. Solutions of $\mathbf{L i 8}$ and $\mathbf{L i 6}$ were prepared by dissolution of the pure crystalline (Li8) and microcrystalline (Li6) powders isolated as described in prior section 2.1 for a variety of concentrations ranging from 2.4 to $60 \mathrm{mM}$ in $\mathrm{H}_{2} \mathrm{O}$ solution and contained in a reusable $1.5 \mathrm{~mm}$ diameter quartz capillary tube for SAXS measurements. To ensure consistency between solutions, the most concentrated solution was prepared first, and less concentrated solutions were obtained by dilution of these solutions. Scattering was measured for 30min or $1 \mathrm{~h}$. After background subtraction and desmearing, the data were analyzed to determine size, size distribution, structure factors and PDDF (pair distance distribution function) using the IRENA macros ${ }^{31}$ within IGOR Pro.

\subsection{Intermediate gel state studies}

Preparation of glassy Li6 and glassy Li8. Saturated aqueous solutions $(\sim 70 \mathrm{mM})$ of Li6 and Li8 were separately prepared by dissolving in water and syringe-filtering ( $0.2 \mu \mathrm{m}$ pores). The filtered solution was placed in a $40 \mathrm{ml}$ beaker, and set in a fumehood for rapid evaporation. The resulting powders were a glassy form, confirmed amorphous by X-ray diffraction. These samples, along with microcrystalline Li6, were used for total X-ray scattering studies. Thermal analysis was performed with a TA Instruments Q600 for thermogravimetric under nitrogen flow with a heating rate of $10{ }^{\circ} \mathrm{C} / \mathrm{min}$.

Total X-ray scattering studies. Total X-ray scattering data on glassy Li6, glassy Li8 and crystalline Li6 were collected at the Advanced Photon Source, beamline 11-ID-B. Samples were prepared by grinding and packing powders into a kapton capillary and then encasing in a quartz capillary to ensure rigidity upon heating. These prepared samples were then mounted in a custom resistive element furnace and nitrogen gas was flowed over the sample during heating. Data was collected at one minute increments with a ramp rate of $10^{\circ} \mathrm{C} / \mathrm{min}$. and a wavelength of $\lambda=0.2114$ angstroms.

Phase purity of the lithium niobate was confirmed using Topas Academic ${ }^{32}$ to fit a simulated diffraction pattern to the crystallized Li6. To analyse the total scattering data, the collected CCD data was 
processed using a custom script utilizing Fit $2 \mathrm{~d}^{33}$ and pdfget $\times 3^{34}$. Fit2d was calibrated against cerium dioxide and used to convert raw CCD data from the 2D area detector for the sample and background to 1D data as a function of Q. Pdfgetx3 was used to subtract the background, perform instrument and sample corrections, and obtain the structure function, $S(Q)$. . The $S(Q)$ was converted to the PDF through a fourier transform according to $\mathrm{G}(\mathrm{r})=2 / \pi \int \mathrm{Q}[\mathrm{S}(\mathrm{Q})-1] \sin (\mathrm{Q}) \mathrm{dQ}$ with a $\mathrm{Q}_{\max }$ value of $28 \AA^{-1}$.

Experimental PDF data of the crystallized $\mathrm{LiNbO}_{3}$ was fit using PDFGui ${ }^{35}$ and a good match between the two was achieved, demonstrating that the cluster transitioned completely to lithium niobate in its standard ferroelectric arrangement.

\subsection{Thin film preparation and characterization}

Prior to deposition, all substrates (sapphire 001 and silicon-001) were rinsed with $\mathrm{H}_{2} \mathrm{O}$, acetone and isopropanol, followed by a $10 \mathrm{~min}$ ash in an $\mathrm{O}_{2}$ plasma. For standard characterization, a 50mM Li6 precursor solution was created by dissolving the clusters in DI water. Films were deposited on substrates by spin coating at $3000 \mathrm{rpm}$ for $30 \mathrm{~s}$, followed by an immediate hot plate cure at $80{ }^{\circ} \mathrm{C}$ for $3 \mathrm{~min}$. The deposited films were then annealed in air at selected temperatures in the range $600-900{ }^{\circ} \mathrm{C}$ for $1 \mathrm{~min}$. Films on Si substrates were used for scanning electron microscopy (SEM), X-ray reflectivity (XRR), and atomic force microscopy (AFM) measurements. SEM images were obtained by an FEI NOVA 230 high resolution SEM using immersion mode. XRR data were collected with $\mathrm{Cu} \mathrm{K} \alpha$ radiation $(40 \mathrm{kV}, 40 \mathrm{~mA})$ on Rigaku Ultima-IV. The beam was conditioned by using a $0.2 \mathrm{~mm}$ divergence slit, a $0.5 \mathrm{~mm}$ scattering slit, and a $0.2 \mathrm{~mm}$ receiving slit. Low-angle reflections from 0 to $5^{\circ}(2 \theta)$ were collected in $0.01^{\circ}$ steps at speed of 0.1 degree/min. Analyses were conducted with X'Pert Reflectivity V1.0 software using sample thickness, surface roughness, and density as fitting parameters. Surface roughness was also evaluated by using a Veeco Di Innova atomic force microscope operated in tapping mode with a Silicon TAP150 AlG-10 probe at a scan rate of $1 \mathrm{~Hz}$. A third-order plane fit was applied to all samples to limit distortion from the cantilever and sample tilt.

\section{Results and Discussion}

\subsection{The precursor salts}

Lithium hexaniobate, $\mathrm{Li}_{8}\left[\mathrm{Nb}_{6} \mathrm{O}_{19}\right] \cdot 15.5 \mathrm{H}_{2} \mathrm{O}$, ( $\left.\mathbf{L i 8}\right)$ was synthesized for this study and characterized by single-crystal X-ray diffraction (see supplementary cif file). However, in its native form it has the incorrect ratio of $\mathrm{Li}: \mathrm{Nb}$ to evolve any pure phase lithium niobate, $\mathrm{LiNbO}_{3}$, upon heating. Thus we converted $\mathbf{L i 8}$ to $\mathrm{Li}_{6}\left[\mathrm{H}_{2} \mathrm{Nb}_{6} \mathrm{O}_{19}\right] \cdot 14 \mathrm{H}_{2} \mathrm{O}$ ( $\mathbf{L i 6}$ ) via acidification in solution and re-isolation in the solidstate by precipitation with ethanol, which resulted in a phase with the correct ratio for the evolution of 
pure-phase $\mathrm{LiNbO}_{3}$. These two phases served as precursors for this study. The hexaniobate cluster, $\left[\mathrm{Nb}_{6} \mathrm{O}_{19}\right]^{8-}$, has been described many times prior. ${ }^{22}$ Briefly it is a superoctahedron of six mutually edgesharing, distorted $\mathrm{Nb}^{\mathrm{V}} \mathrm{O}_{6}$ octahedra (also presented later in table $2 \&$ figure 5). The central oxygen is $\mu_{6}$, bonded to all six $\mathrm{Nb}$ with long Nb-O bonds, $\sim 2.35 \AA$. Trans to this for all six $\mathrm{Nb}$ atoms is a $\mathrm{Nb}=\mathrm{O}$ double bond, $\sim 1.78 \AA$. The $\mathrm{Nb}-\mathrm{O}$ bond lengths of the twelve $\mu_{2}-\mathrm{ONb}_{2}$ are $\sim 2.0 \AA$. In $\mathbf{L i 6}$, the cluster is diprotonated, $\left[\mathrm{H}_{2} \mathrm{Nb}_{6} \mathrm{O}_{19}\right]^{6-}$, and we assume, based on many prior structures, ${ }^{22}$ that the protons reside on the $\mu_{2}-\mathrm{ONb}_{2}$ bridging oxos, which lengthens the $\mathrm{Nb}-\mathrm{O}(\mathrm{H})$ bond distance to $2.2 \AA$. In the structure of $\mathbf{L i 8}$ and previously reported structures of lithium hexaniobate, ${ }^{21,27}$ the lithium forms its own adamantoid cluster with water, see figure 2a. Moreover, the lithium-water lattice forms an interconnected network of the adamantoid clusters, edge-sharing octahedral, and an 8-member ring of alternating lithium and water (figure 2b). The prevalence of this Li-water cluster in lithium hexaniobate crystalline lattices indicates that this is a stable arrangement for $\mathrm{Li}^{+}$-water at the high $\mathrm{pH}(>12)$ conditions of self-assembly and crystallization. Li6, on the other hand, exhibits poorer crystallinity (powder diffraction pattern shown in figure SI1), as we were unable to grow a good-quality single crystals for structure determination. The $\mathrm{Li}: \mathrm{Nb}$ of both Li6 and Li8 is confirmed by wet-chemical analysis. We also identify the hexaniobate cluster in Li6 by the pair-distribution function (PDF) analysis of this precursor, which is discussed later.

\subsection{The precursor solutions}

We utilized SAXS (small-angle X-ray scattering) to evaluate the size, shape, and interspeciesinteractions of Li6 and Li8 dissolved in water. Before any analyses were performed, we noted qualitatively poorer solubility of the Li8 salt. We analyzed three concentrations of Li6 and Li8 in water; the minimum concentration was limited by the signal to noise ratio of the scattering curve, and the maximum concentration represented the concentrations used for film deposition. The $\log ($ intensity)- $\log (\mathrm{q})$ $\left(\mathrm{nm}^{-1}\right)$ plots for all six measurements are shown in figure 3; and pertinent calculated form and structure factors from curve fitting analyses are compiled in Table 1. The pair distance distribution functions (PDDF) of $2.4 \mathrm{mM}$ solutions of both Li6 and Li8 show symmetric Gaussian curves (see figure SI2) that indicate no polydispersity or ion-association. Additionally, $\mathrm{R}_{\mathrm{g}}$ values determined from two different methods (Guinier approximation and PDDF) ${ }^{31}$ suggest a monodisperse solution of $\left[\mathrm{H}_{\mathrm{x}} \mathrm{Nb}_{6} \mathrm{O}_{19}\right]^{(8-\mathrm{x})-}($ Table 1). These experimental $R_{g}$ values agree reasonably well with the $R_{g}$ calculated from the radius of the Lindqvist ion (from structural data, $4.2 \AA$ ), assuming an approximately spherical scatterer $(3.25 \AA$, radius $\left.=\mathrm{R}_{\mathrm{g}} * \sqrt{ } 5 / 3\right)$.

On the other hand, the higher concentration solutions from which the films are deposited reveal altogether different behaviors. The Li6 24 and $60 \mathrm{mmol}$ concentration solutions have a structure factor (the small 'bump' around $\log \mathrm{q}=2$, see figure 3), indicating the clusters are interacting with each other 
with a center-to-center distance of $\sim 26 \AA$. Moreover, the PDDF curves (radial probability p(r) as a function of radius, $\AA$, from the edge of the particle) show a second smaller peak which indicates dimer formation (figure 4). This is also seen in the slightly large $\mathrm{R}_{\mathrm{g}}$ determined from the PDDF fit compared to that obtained from the Guinier approximation.

Since we are not able to grow diffraction quality single-crystals of Li6, we turn to the many solidstate structures we have available for $\mathrm{A}_{6}\left[\mathrm{H}_{2} \mathrm{Nb}_{6} \mathrm{O}_{19}\right] \mathrm{xH}_{2} \mathrm{O}$ (A=alkali) salts ${ }^{22}$ for a structural model of the dimerization observed in the SAXS data. In $\mathrm{K}^{+}, \mathrm{Rb}^{+}$, and $\mathrm{Cs}^{+}$salts of $\left[\mathrm{H}_{2} \mathrm{Nb}_{6} \mathrm{O}_{19}\right]$, the protons reside on adjacent $\mu_{2}$-O ligands. This diprotonated edge is mutually $\mathrm{H}$-bonded to the same face of a second cluster in the solid-state lattice (see Fig. 4 inset). This dimer has also been observed for the related decavanadate cluster in both the solid-state ${ }^{36}$ and in solution. ${ }^{37}$ Thus solid-state and solution evidence together suggest dimerization of diprotonated clusters as shown in Fig. 4 is not uncommon. The long axis of this dimer specie is $\sim 15 \AA$, which is in agreement with linear extent of the second peak of the $\mathrm{P}(\mathrm{r})$ curve. Using SolX ${ }^{38,39}$ and the solid-state structure of a $\left[\mathrm{H}_{2} \mathrm{Nb}_{6} \mathrm{O}_{19}\right]^{6-}$ dimer, ${ }^{22}$ we calculated theoretical scattering curves for the specie shown in the inset of figure 4, and generated PDDF plots of both the dimer and the monomer forms. Linear combinations of these curves (figure SI3) suggest the 24 and $60 \mathrm{mM} \mathrm{Li6}$ solutions consist of $80-90 \%$ unassociated $\left[\mathrm{H}_{2} \mathrm{Nb}_{6} \mathrm{O}_{19}\right]^{6-}$ and $10-20 \%$ dimerized $\left[\mathrm{H}_{2} \mathrm{Nb}_{6} \mathrm{O}_{19}\right]^{6-}$.

The prominent feature of the $\mathbf{L i 8} \log (\mathrm{I}) \log (\mathrm{q})$ plots for 25 and $50 \mathrm{mM}$ solutions (figure 3) is a distinct upward slope in the low-q region. This is indicative of polydisperse solutions, and these curves were fit with two populations of scatterers: the population of smaller scatterers is consistent with $\left[\mathrm{Nb}_{6} \mathrm{O}_{19}\right]^{8-}$ monomer while the population of larger scatterers is likely an aggregate of multiple Lindqvist ions (Table 1). The PDDF curves (figure SI2) could only be fit for the high-q region of the curve which is dominated by the population of smaller scatterers. Both the $\mathrm{R}_{\mathrm{g}}$ and the symmetric $\mathrm{P}(\mathrm{r})$ curve shape indicate unassociated monomers; and these make up the majority of the solution. However, the low-q range is fitted to a second minor population of larger scatters; $46 \AA$ in radius $(0.14 \%$ of total volume of scatterers) for the $25 \mathrm{mM}$ solution and $22 \AA$ in radius (1.6\% of total volume of scatterers) for the $50 \mathrm{mM}$ solution. We have interpreted this as incipient crystallization of the Li8 salt, and the large aggregates are still-soluble nuclei. The smaller, more abundant nuclei in the higher concentration solution are indeed consistent with crystallization/precipitation behavior: smaller and more abundant crystals are grown from a solution of higher concentration, and larger and fewer crystals grow from a lower concentration solution.

Finally, we return to the solid-state structure of $\mathbf{L i 8}$ to discuss why these large aggregates form in the solution, whereas as dimerization is the more prevalent association mechanism for Li6. In Li8 solutions, we may expect cationic lithium-water clusters that are evident in solid-state structures to persist. Polynuclear anions plus polynuclear cations $\left(\left[\mathrm{Nb}_{6} \mathrm{O}_{19}\right]^{8-}\right.$ and lithium-water clusters, respectively) 
result in poor solubility, presumably due to high negative enthalpy of crystallization, as has been observed

for aluminium polycation Keggin ions with tungstate polyanion Keggin ions. ${ }^{40}$ This likely explains why we observe nucleation in these solutions via SAXS, as well as qualitatively poorer solubility of Li8 compared to Li6. On the other hand, the lower $\mathrm{pH}(\sim 10)$ of the Li6 solutions appears to both disrupt the assembly of the $\mathrm{Li}^{+}$-water clusters and favor dimerization via cluster protonation and hydrogen bonding. This is self-evident by the inability to crystallize Li6, as well as the observed different solution behavior.

\subsection{The intermediate gel state}

The intermediate gel state is deposited on a substrate via spin coating of the precursor solution, see figure 1. With rotation of the substrate, the solution spreads and evaporates very rapidly. Obtaining a gel is one of the most crucial steps, and usually the least well-understood step in the transition from precursor to final thin film product. An optimal gel is continuous and smooth, and usually an amorphous network. To characterize the intermediate gel-state and its conversion to metal oxide, we produced glassy samples (i.e. not crystalline) of $\mathbf{L i 6}$ and $\mathbf{~ L i 8 ~ i n ~ a ~ b u l k ~ f o r m . ~ T h e s e ~ g l a s s y ~ L i 6 ~ a n d ~ L i 8 ~ s a m p l e s ~ l a c k ~ l o n g - r a n g e ~}$ order, and thus are suitable for characterization via total X-ray scattering to determine the local structure in addition to the long-range structure that evolves with in-situ heating.

Figure 5 shows the room temperature PDF (pair distribution function) of $\mathbf{L i 6}$ and $\mathbf{L i 8}$, in addition to the simulated PDF for a single $\left[\mathrm{Nb}_{6} \mathrm{O}_{19}\right]^{8-}$ cluster and a dimer of $\left[\mathrm{H}_{2} \mathrm{Nb}_{6} \mathrm{O}_{19}\right]^{6-}$ clusters associated by hydrogen-bonding. Also shown is a structural representation of the $\left[\mathrm{H}_{2} \mathrm{Nb}_{6} \mathrm{O}_{19}\right]^{6-}$ dimer, and atom-atom distances contributing to the PDF peaks are listed in Table 2. For this structural representation, we used a previously published diprotonated Lindqvist structure $\mathrm{Cs}_{6}\left[\mathrm{H}_{2} \mathrm{Nb}_{6} \mathrm{O}_{19}\right] 9 \cdot \mathrm{H}_{2} \mathrm{O}^{22}$ to describe pair distances within the cluster, between two mutually H-bonded clusters and between clusters and water molecules. Dominating are two peaks attributed to the $\mathrm{Nb}-\mathrm{Nb}$ distances (3.3 and $4.8 \AA$ ) within a single cluster, showing preservation of the $\left[\mathrm{Nb}_{6} \mathrm{O}_{19}\right]^{8-}$ ion in this intermediate gel state. The peak centered at $2.0 \AA$ is the $\mathrm{Nb}-\mathrm{O}$ distance of the $\mu_{2}-\mathrm{ONb}_{2}$ bonds. In both the calculated and experimental PDFs, we do not see a distinct $\mathrm{Nb}=\mathrm{O}(\sim 1.75 \AA)$ peak, as it is overlapping with the aforementioned $2.0 \AA$ peak. On the other hand, we distinctly observe the $2.4 \AA$ peak that corresponds with the $\mathrm{Nb}-\mathrm{O}$ distance between the central O and the six $\mathrm{Nb}$ of a cluster. It is unclear why the $\mathrm{Nb}=\mathrm{O}$ peak is not distinct in the simulated PDF. In the glassy Li6 and Li8 samples, the clusters are distorted via association with lattice water, $\mathrm{Li}^{+}$and $\mathrm{H}^{+}$, which likely results in a range in Nb-O distances from 1.7-2.2 $\AA$, consistent with the base width of this peak. In general, the PDFs of $\mathbf{L i 6}$ and $\mathbf{L i 8}$ are very similar. The peaks between $r \sim 6-8 \AA$ are most likely related to cluster-cluster association, as peaks in this region are observed in the simulated PDF for the dimer. However, we do not expect these to match exactly between simulation and experiment, because the 
simulation provides only one arrangement, but these samples without long range order have many possible arrangements of the clusters. Peak $3(2.7 \AA)$ is a very common H-bonding distance between two water molecules or water and a cluster oxygen. We have assigned both peak 3 and peak 6 to O-O distances between clusters and water in the disordered lattice. These are not observed in the simulations which are dominated by $\mathrm{Nb}-\mathrm{Nb}$ distances. Contributions from $\mathrm{Li}-\mathrm{O}$ and $\mathrm{Li}-\mathrm{Li}$ distances are diminutive, as the scattering intensity scales with atomic number.

The variable temperature PDFs of $\mathbf{L i 6}$ and $\mathbf{~ L i 8 , ~ f r o m ~ r o o m ~ t e m p e r a t u r e ~ t o ~} 700{ }^{\circ} \mathrm{C}$ reveal differences in their evolution to crystalline lithium niobate phases (figure 6). The Bragg diffraction peaks (top spectra in figure 6) for heated $\mathbf{~ L i 8 ~ b e c o m e ~ e v i d e n t ~ a r o u n d ~} 300{ }^{\circ} \mathrm{C}$, and approximately $400{ }^{\circ} \mathrm{C}$ for $\mathbf{~ L i 6}$. Simultaneous with the appearance of diffraction peaks for $\mathbf{L i 8}$, the short $\mathrm{Nb}=\mathrm{O}$ distance at $1.75 \AA$ becomes evident and the $2.0 \AA \mathrm{Nb}-\mathrm{O}$ distance loses intensity. This may be a direct result of dehydration and therefore decreased hydrogen-bonding of water with $\mathrm{Nb}=\mathrm{O}$. Additionally, both the diffraction peaks and the PDF of heated $\mathbf{L i 8}$ reveal that two phases crystallize simultaneously: ordered $\mathrm{Li}_{3} \mathrm{NbO}_{4}$ and perovskite $\mathrm{LiNbO}_{3}$. (see fig SI8 for Pawley fit of $\mathbf{L i 8}$ at $600{ }^{\circ} \mathrm{C}$ ) Within the lattice of ordered $\mathrm{Li}_{3} \mathrm{NbO}_{4}$, there is an $\mathrm{Nb}$-tetramer of edge-sharing $\mathrm{Nb}$ octahedra that resembles a fragment of the Lindqvist ion, see figure 7. This phase likely forms because of the similarity of its local structure to that of glassy Li8. At $\sim 400{ }^{\circ} \mathrm{C}$, the $1.75 \AA$ peak diminishes in correlation with rise in the $2.0 \AA$ peak; and once again around 600 ${ }^{\circ} \mathrm{C}$, these peaks swap intensity. These events correlate with conversion of $\mathrm{Li}_{3} \mathrm{NbO}_{4}$ to $\mathrm{LiNbO}_{3}$, and formation of $\mathrm{Nb}_{2} \mathrm{O}_{5}$ as a result of lithium volatilization, respectively. On the other hand, Li6 converts directly to $\mathrm{LiNbO}_{3}$ at $400{ }^{\circ} \mathrm{C}$, with no other intermediates or products detected in either the X-ray PDF or the X-ray diffraction data (see also figs. SI9 \& SI10 for Pawley and PDFgui fits, respectively). These results lead to the question of why does ordered $\mathrm{Li}_{3} \mathrm{NbO}_{4}$ form from $\mathbf{~} \mathbf{~ i 8}$ and not $\mathbf{~} \mathbf{~ i 6}$, when they have similar local structure featuring the Lindqvist ion? Two possible hypotheses include: 1) the protonated state of Li6 Lindqvist ions renders it more reactive to atomic level mobility that is necessary to rearrange and form $\mathrm{LiNbO}_{3}$ with less $\mathrm{Nb}-\mathrm{O}-\mathrm{Nb}$ connectivity (fig. 7) or 2) glassy Li8, like its crystalline form, has more short-range order in the Li-water species than Li6. To summarize, these X-ray scattering results provide compelling direct evidence that atomic-level structure in a precursor profoundly affects its evolution to a metal oxide product.

The thermogravimetric curves (figure 8) provide further information regarding the conversion of Li6 and Li8 (crystalline and glassy) to lithium niobate phases. The higher weight loss of the Li8 phase quantitatively corresponds with evaporation of lithium oxide. This agrees with the X-ray scattering studies discussed above, showing formation of $\mathrm{Nb}_{2} \mathrm{O}_{5}$ upon loss of lithium above $600{ }^{\circ} \mathrm{C}$. Moreover, these results are also confirmed by the ex-situ heating-X-ray diffraction studies of Li6 and Li8 (see supplemental) This is particularly evident in the glassy sample, as there is a distinct weight-loss event 
above $600{ }^{\circ} \mathrm{C}$, in correlation with the formation of more $\mathrm{Nb}$-rich phases in both the in-situ and ex-situ heating studies. Crystalline Li6 and glassy Li6 have more similar dehydration behaviour than crystalline Li8 and glassy Li8. This is because Li6 is poorly crystalline, and its arrangement of ions and water molecules is likely more similar to the glassy state than the case of Li8. The less ordered phases lose water and lithium oxide in more distinct steps, compared to crystalline Li8. Initially this seems counterintuitive, but it is probably because the poorly ordered phases are more dense and therefore species are less readily volatilized.

\subsection{The metal oxide coating}

Crystallization of a dissolved precursor on a substrate instead of gel-formation can be detrimental to film quality, because it does not provide a continuous coating. The disparate behaviours of Li6 and Li8 in solution as observed by SAXS and interpreted by the solid-state structures suggest they should also exhibit different film deposition character. Figure 9a shows surface and cross-section SEM images of a typical film from Li6 dehydrated at $80{ }^{\circ} \mathrm{C}(\mathrm{a} \& \mathrm{~b})$ and annealed at $600{ }^{\circ} \mathrm{C}(\mathrm{c} \& \mathrm{~d})$. The surface of the film dehydrated at $80{ }^{\circ} \mathrm{C}$ is very smooth: no features are discernible in the top-view SEM. The high-resolution cross-section SEM image reveals a continuous and dense film. For the crystallized film annealed at 600 ${ }^{\circ} \mathrm{C}$, grain growth and grain boundary formation become apparent in both top-view and cross-section SEM images. It is noteworthy that all films from Li6 are smooth and continuous without visible cracks and voids even after undergoing shrinkage associated with drying and crystallization. X-ray reflectivity (XRR) and ellipsometry data quantified film thickness, roughness, and density. These data for the $80{ }^{\circ} \mathrm{C}$ (3min) and $600{ }^{\circ} \mathrm{C}(1 \mathrm{~min})$ heated films, along with the model fits, are compiled in the Supplementary Information (fig. SI6 \& SI7). The surface roughness for the film dried at $80{ }^{\circ} \mathrm{C}$ for $3 \mathrm{~min}$ is $0.3 \mathrm{~nm}$, and it increases to about $1.3 \mathrm{~nm}$ after annealing at $600{ }^{\circ} \mathrm{C}$. The in-situ heating, X-ray scattering studies discussed prior showed crystallization initiated at $400 \mathrm{C}$. The density increases from 3.0 to $4.3 \mathrm{~g} / \mathrm{cm}^{3}$ from the room-temperature gel state to the $600{ }^{\circ} \mathrm{C}$ annealed film. The $4.3 \mathrm{~g} / \mathrm{cm}^{3}$ density corresponds to $92 \%$ of the theoretical density of $\mathrm{LiNbO}_{3}$, which is similar to that reported prior for $\mathrm{LiNbO}_{3}$ films deposited from aqueous solution. ${ }^{30}$ To summarize briefly, Li6 precursor produced pure-phase $\mathrm{LiNbO}_{3}$ (fig. 10) films with continuous coverage.

On the other hand, $\mathbf{L i 8}$ produced films that are composed of both $\mathrm{Li}_{3} \mathrm{NbO}_{4}$; and $\mathrm{LiNbO}_{3}$, and exhibit island-growth morphology (fig. $10 \&$ fig. 9b). This film was likewise annealed at $600{ }^{\circ} \mathrm{C}$, and the euhedral 'islands' of lithium niobate phases preserve the morphology of the Li8 crystalline salt. It is evident that Li8 is crystallizing on the substrate upon spin coating and rapid evaporation of the water. These results relate directly to the behavior of Li6 and Li8 in solution as observed by SAXS: 
crystallization of Li-water adamantoid cationic clusters with anionic Lindqvist ion clusters is energetically favorable. Therefore, the intermediate gel formation necessary for continuous metal oxide coating is inhibited.

\section{Conclusions}

This work illustrates the importance of both manipulating and interpreting the atomic level interactions of aqueous species that are precursors to materials self-assembled in water. Almost always in aqueous chemistry, there are counterions which are considered 'innocent'; and in the case of solution deposition, these counterion species need to be removed (such as by ion-exchange, vaporization or combustion) if they are not a desired component of the targeted thin film product. In the current study, the counterions are both byproducts $\left(\mathrm{H}^{+}\right.$or excess $\left.\mathrm{Li}^{+}\right)$and film components (stoichiometric $\mathrm{Li}^{+}$); yet all significantly influence the film properties. By simply replacing $25 \%$ of the $\mathrm{Li}^{+}$counterions with $\mathrm{H}^{+}$, the interactions between the anionic metal-oxo clusters, alkali counterions, and water molecules change dramatically, as observed in solution behavior, dehydration and crystallization of the gel state, and the resulting thin film morphologies and phases. This evolution in solution and subsequent gel chemistry made the difference between an excellent precursor solution and a problematic precursor solution; the former producing a continuous dense coating of a single phase and the latter exhibiting island growth and formation of mixed phases. Several explanations are possible in this particular case; and it is likely that all factors contribute: 1) The lithium-water adamantoid clusters of the Li8 precursor that impart poor solubility and high lattice crystallization energy are disrupted by the $\mathrm{pH}$ decrease of the Li6 solution, 2) the more prevalent dimer association of the $\left[\mathrm{H}_{2} \mathrm{Nb}_{6} \mathrm{O}_{19}\right]^{6-}$ cluster competes with association with the lithium-water clusters, resulting in a more soluble precursor chemistry, or 3) the dimer association dominates in the transition from solution to a solid gel state, and serves as the 'glue' for continuous and smooth substrate coverage. Moreover, extensive inter-cluster H-bonding, and H-bonding between water molecules and the clusters in the amorphous gel state may weaken the intracluster bonds and ease rearrangement into the final metal oxide product. While each solution-to-gel-to-solid system for aqueous preparation of metal oxides has unique characteristics and challenges associated with its specific chemistry; the universal importance of interaction of ions with each other and with water in solutions and gels cannot be underestimated.

\section{Acknowledgement}

This material is based upon work supported by the National Science Foundation under Grant No. CHE1102637. Use of the Advanced Photon Source, an Office of Science User Facility operated for the U.S. Department of Energy (DOE) Office of Science by Argonne National Laboratory, was supported by the 
U.S. DOE under Contract No. DE-AC02-06CH11357. Data was collected at beamline 11-ID-B at the Advanced Photon Source, Argonne National Laboratory. We also thank Karena Chapman and Kevin Beyer for assistance with the PDF experiments. 


\section{References}

(1) Sunde, T. O. L.; Garskaite, E.; Otter, B.; Fossheim, H. E.; Saeterli, R.; Holmestad, R.; Einarsrud, M. A.; Grande, T. J Mater Chem 2012, 22, 15740.

(2) Vayssieres, L. Adv Mater 2003, 15, 464.

(3) Jiang, K.; Anderson, J. T.; Hoshino, K.; Li, D.; Wager, J. F.; Keszler, D. A. Chem Mater 2011, 23, 945.

(4) Keszler, D. A.; Anderson, J. T.; Meyers, S. T. In Solution Processing of Inorganic Materials; Mitzi, D. B., Ed.; John Wiley \& Sons, Inc.: 2009, p 109.

(5) Mehring, M. Coordin Chem Rev 2007, 251, 974.

(6) Mensinger, Z. L.; Gatlin, J. T.; Meyers, S. T.; Zakharov, L. N.; Keszler, D. A.; Johnson, D. W. Angew Chem Int Edit 2008, 47, 9484.

(7) Colfen, H.; Schnablegger, H.; Fischer, A.; Jentoft, F. C.; Weinberg, G.; Schlogl, R. Langmuir 2002, 18, 3500.

(8) Anderson, J. T.; Munsee, C. L.; Hung, C. M.; Phung, T. M.; Herman, G. S.; Johnson, D. C.; Wager, J. F.; Keszler, D. A. Adv Funct Mater 2007, 17, 2117.

(9) Llordes, A.; Hammack, A. T.; Buonsanti, R.; Tangirala, R.; Aloni, S.; Helms, B. A.; Milliron, D. J. J Mater Chem 2011, 21, 11631.

(10) Llordes, A.; Garcia, G.; Gazquez, J.; Milliron, D. J. Nature 2013, 500, 323.

(11) Pearson, A.; Bhosale, S.; Bhargava, S. K.; Bansal, V. Acs Appl Mater Inter 2013, 5, 7007.

(12) Wang, S. M.; Liu, L.; Chen, W. L.; Zhang, Z. M.; Su, Z. M.; Wang, E. B. J Mater Chem A 2013, 1, 216.

(13) Rodel, J.; Jo, W.; Seifert, K. T. P.; Anton, E. M.; Granzow, T.; Damjanovic, D. J Am Ceram Soc 2009, 92, 1153.

(14) Bokov, A. A.; Ye, Z. G. J Mater Sci 2006, 41, 31.

(15) Chen, F. J Appl Phys 2009, 106.

(16) Kip, D. Appl Phys B-Lasers O 1998, 67, 131.

(17) Ida, S.; Ogata, C.; Eguchi, M.; Youngblood, W. J.; Mallouk, T. E.; Matsumoto, Y. J Am Chem Soc 2008, 130, 7052.

(18) Soljacic, M.; Joannopoulos, J. D. Nat Mater 2004, 3, 211.

(19) Osterloh, F. E. Chem Soc Rev 2013, 42, 2294.

(20) Anderson, T. M.; Rodriguez, M. A.; Bonhomme, F.; Bixler, J. N.; Alama, T. M.; Nyman, M. Dalton T 2007, 4517.

(21) Anderson, T. M.; Thoma, S. G.; Bonhomme, F.; Rodriguez, M. A.; Park, H.; Parise, J. B.; Alam, T. M.; Larentzos, J. P.; Nyman, M. Cryst Growth Des 2007, 7, 719.

(22) Nyman, M.; Alam, T. M.; Bonhomme, F.; Rodriguez, M. A.; Frazer, C. S.; Welk, M. E. J Clust Sci 2006, 17, 197.

(23) Du, Y. Y.; Zhang, Y.; Huang, K. K.; Wang, S.; Yuan, L.; Feng, S. H. Dalton T 2013, 42, 8041.

(24) Goh, G. K. L.; Lange, F. F.; Haile, S. M.; Levi, C. G. J Mater Res 2003, 18, 338.

(25) Handoko, A. D.; Goh, G. K. L. Crystengcomm 2013, 15, 672.

(26) Kong, X. G.; Hu, D. W.; Wen, P. H.; Ishii, T.; Tanaka, Y.; Feng, Q. Dalton T 2013, 42, 7699.

(27) Nyman, M.; Anderson, T. M.; Provencio, P. P. Cryst Growth Des 2009, 9, 1036.

(28) Nyman, M.; Rodriguez, M. A.; Rohwer, L. E. S.; Martin, J. E.; Waller, M.; Osterloh, F. E. Chem Mater 2009, 21, 4731.

(29) Nyman, M.; Rodriguez, M. A.; Shea-Rohwer, L. E.; Martin, J. E.; Provencio, P. P. J Am Chem Soc 2009, 131, 11652.

(30) Ono, S.; Hirano, S. I. J Ceram Soc Jpn 2007, 115, 801.

(31) Ilavsky, J.; Jemian, P. R. J Appl Crystallogr 2009, 42, 347. 
(32) Coelho, A.; 5 ed.; Coelho Software: Brisbane, 2012.

(33) Hammersley, D. A.; 12.077 ed.; European Synchrotron Radiation Facility: 2005.

(34) P. Juhás and T. Davis, C. L. F., S. J. L. Billinge J. Appl. Cryst. 2013, 560.

(35) C. L. Farrow, P. J., J. W. Liu, D. Bryndin, E. S. Božin, J. Bloch, Th. Proffen and S. J. L. Billinge J. Phys.: Condens. Matter 2007, 19.

(36) Day, V. W.; Klemperer, W. G.; Maltbie, D. J. J Am Chem Soc 1987, 109, 2991.

(37) Kojima, T.; Antonio, M. R.; Ozeki, T. J Am Chem Soc 2011, 133, 7248.

(38) Tiede, D. M.; Zhang, R. T.; Chen, L. X.; Yu, L. H.; Lindsey, J. S. J Am Chem Soc 2004, 126, 14054.

(39) Zhang, R. T.; Thiyagarajan, P.; Tiede, D. M. J Appl Crystallogr 2000, 33, 565.

(40) Son, J. H.; Kwon, Y. U.; Han, O. H. Inorg Chem 2003, 42, 4153. 


\section{Tables}

Table 1. Calculated parameters from SAXS data of precursor solutions

\begin{tabular}{|c|c|c|c|c|}
\hline \multicolumn{5}{|c|}{ Form Factors: Rg, Ă } \\
\hline & Guinier approximation & PDDF & Modeling II ${ }^{a}$ & $\begin{array}{l}\text { Ratio of two } \\
\text { phases }\end{array}$ \\
\hline 2.4 mM Li6 & $3.5(1)$ & $3.1(1)$ & & \\
\hline $2.5 \mathrm{mM} \mathrm{Li8}$ & $3.4(1)$ & $3.3(4)$ & & \\
\hline 24 mM Li6 & $3.6(3)$ & $4.4(2)$ & $3.6(2)$ & N/A \\
\hline 25 mM Li8 & $3.9(3)$ & $3.4(3)$ & $3.4 / 46.0$ & $722 / 1$ \\
\hline 60 mM Li6 & $3.4(3)$ & $4.4(3)$ & $3.6(2)$ & N/A \\
\hline 50 mM Li8 & $4.8(3)$ & $4.0(1)$ & $3.5 / 22.2$ & $62 / 1$ \\
\hline \multicolumn{5}{|c|}{\begin{tabular}{|c|} 
Structure Factors \\
\end{tabular}} \\
\hline \multicolumn{3}{|c|}{ Number of scatters in nearest neighbor sphere (phi) } & $\begin{array}{c}\text { Center-to-center } \\
\text { distance of scatters }(\AA)\end{array}$ & \\
\hline 24 mM Li6 & \multicolumn{2}{|c|}{0.6} & 27 & \\
\hline 60 mM Li6 & \multicolumn{2}{|c|}{0.6} & 26 & \\
\hline
\end{tabular}


Table 2. Peak assignments of glassy Li6 and Li8 PDFs (see figure 5)

\begin{tabular}{|c|c|c|c|c|}
\hline Peak & $\begin{array}{l}\text { Distance }(\AA) \\
\text { from PDF }\end{array}$ & $\begin{array}{l}\text { Distance }(\AA) \text { from } \\
\text { structural model }^{1}\end{array}$ & $\begin{array}{c}\text { Description of atom } \\
\text { pair(s) }\end{array}$ & Examples of atom pair(s) \\
\hline 1 & 2.0 & 2.0 & $\mu_{2} \mathrm{O}-\mathrm{Nb}$ & Nb6-O1 \\
\hline 2 & 2.2 & 2.4 & $\mu_{6} \mathrm{O}-\mathrm{Nb}$ & O6-Nb6 \\
\hline 3 & 2.9 & 2.7 & $\mu_{2}-\mathrm{O}---\mathrm{OH}_{2}$ & O1-O25 \\
\hline 4 & 3.4 & 3.3 & cis-Nb-Nb & Nb6-Nb1 \\
\hline 5 & 3.8 & 3.9 & $\mathrm{Nb}---\mathrm{OH}_{2}$ & $\mathrm{Nb5-O} 25$ \\
\hline 6 & 4.1 & 4.2 & $\begin{array}{c}\mu_{2}-\mathrm{O}-\mathrm{Nb} \text { of adjacent } \mathrm{H}- \\
\text { bonded clusters }\end{array}$ & $\mathrm{O} 18-\mathrm{Nb} 5$ \\
\hline 7 & 4.8 & 4.8 & trans $-\mathrm{Nb}-\mathrm{Nb}$ & Nb6-Nb3 \\
\hline 8 & 5.1 & 5.2 & $\begin{array}{l}\mathrm{Nb}-\mathrm{Nb} \text { of adjacent } \mathrm{H} \text {-bonded } \\
\text { clusters }\end{array}$ & $\mathrm{Nb5}-\mathrm{Nb3}$ \\
\hline
\end{tabular}

${ }^{1}$ Two mutually $\mathrm{H}$-bonded $\left[\mathrm{H}_{2} \mathrm{Nb}_{6} \mathrm{O}_{19}\right]^{6-}$ clusters in $\mathrm{Cs}_{6}\left[\mathrm{H}_{2} \mathrm{Nb}_{6} \mathrm{O}_{19}\right] 9 \mathrm{H}_{2} \mathrm{O}(\mathrm{Cs} 2)^{22}$ was used as a model to identify pair distances in the experimental data. 
Figure 2
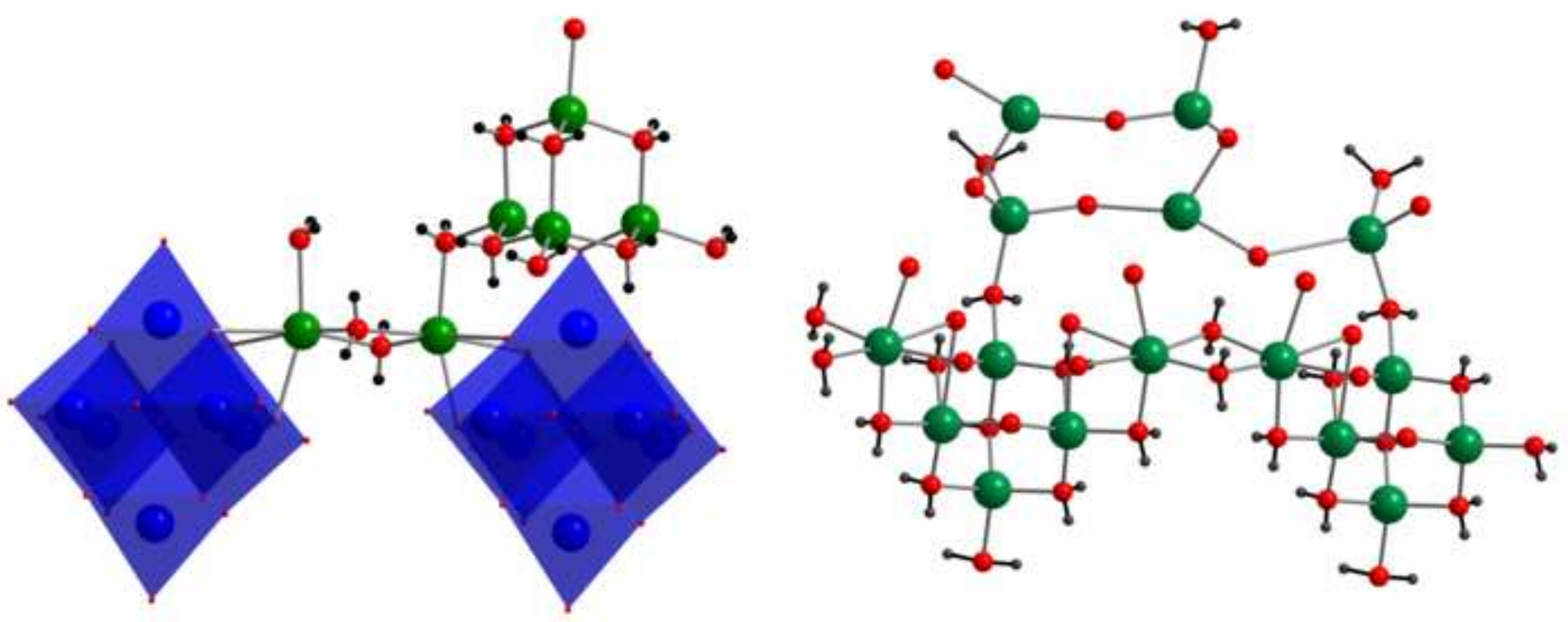
Figure 3
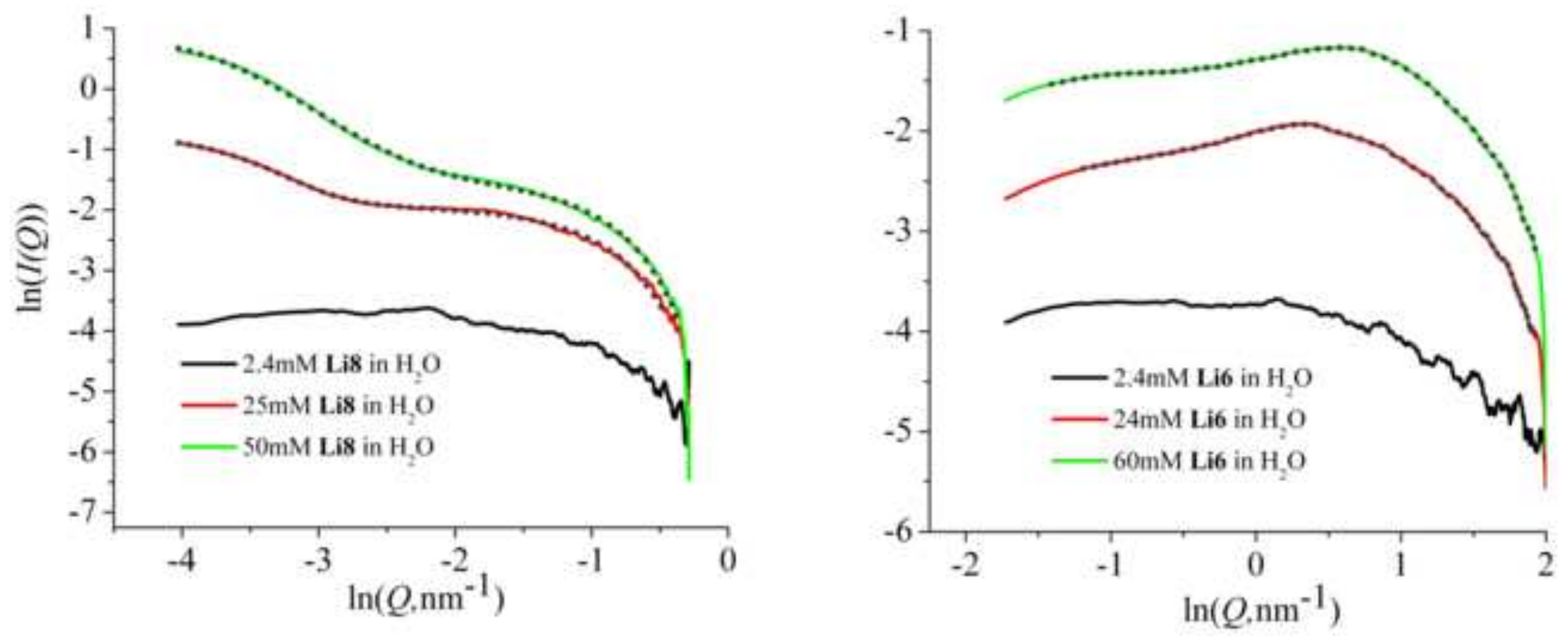
Figure 4

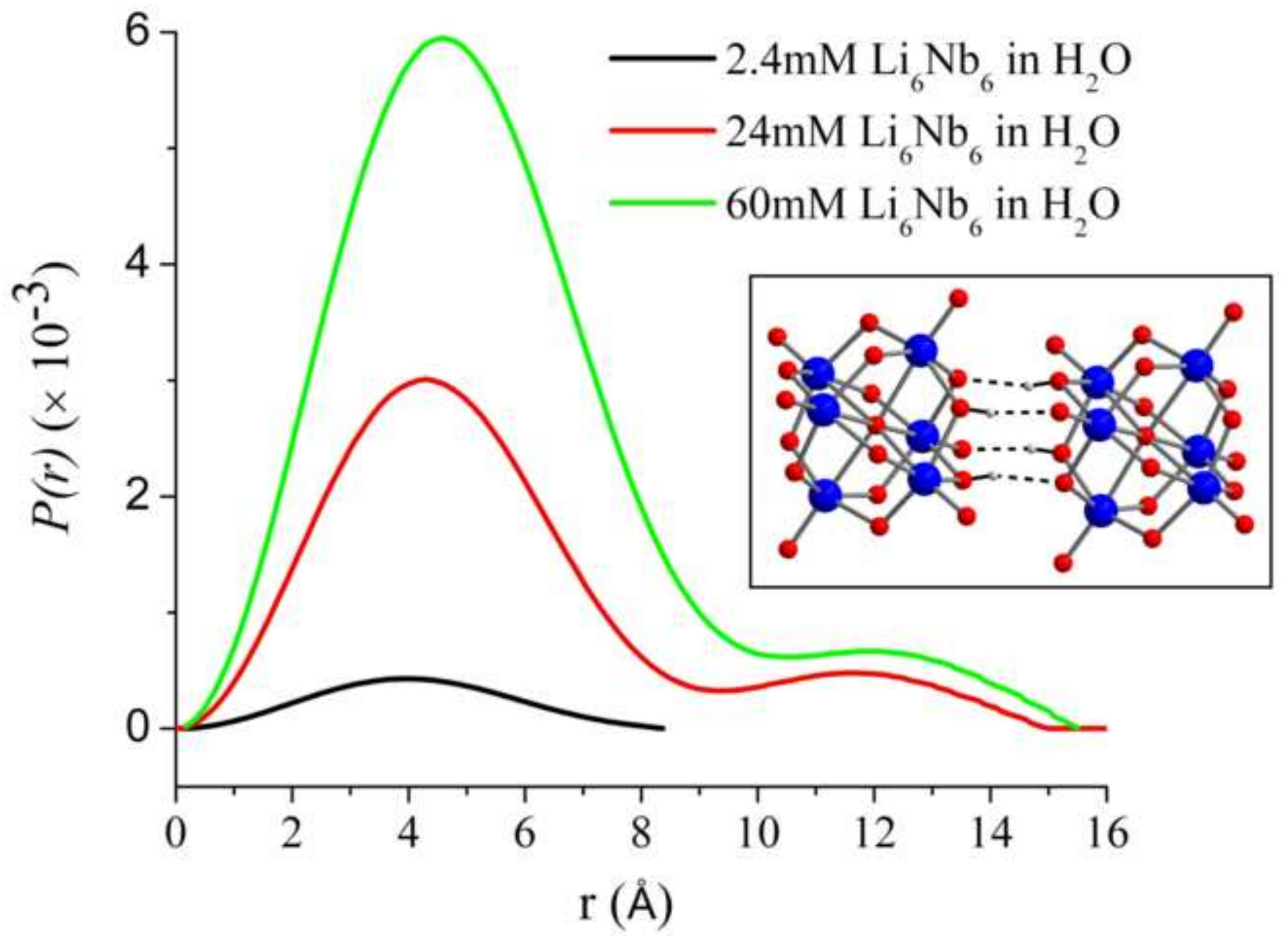


Figure 5

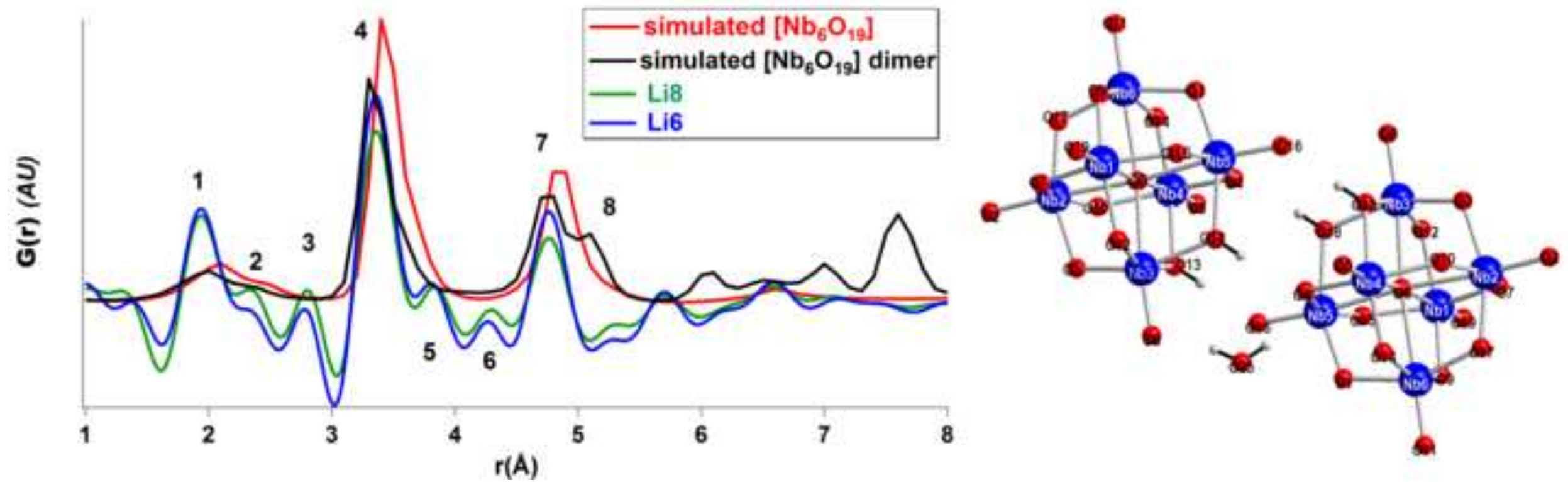


Figure 6

Li6Glass I(Q)
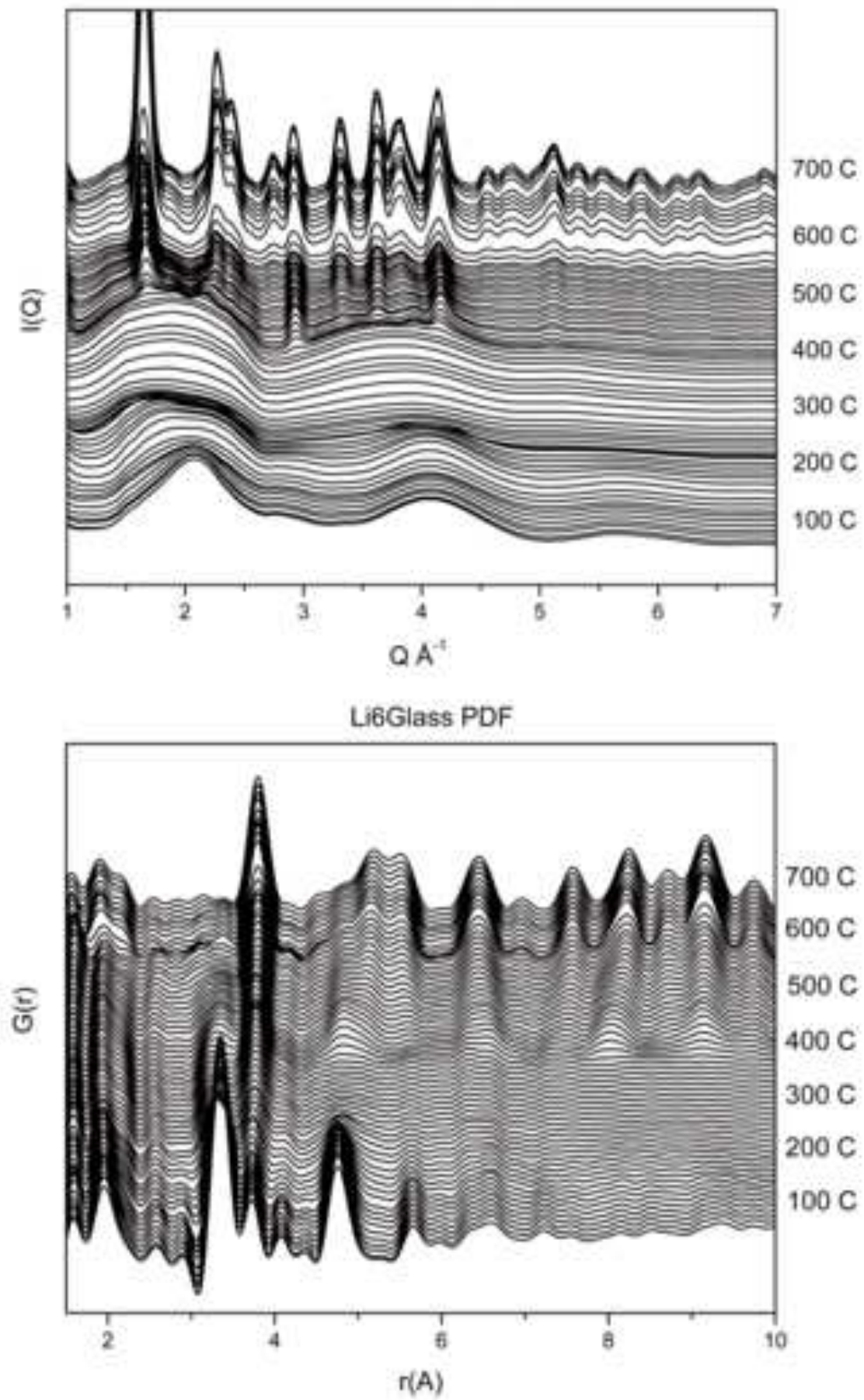

LiBGlass I(Q)
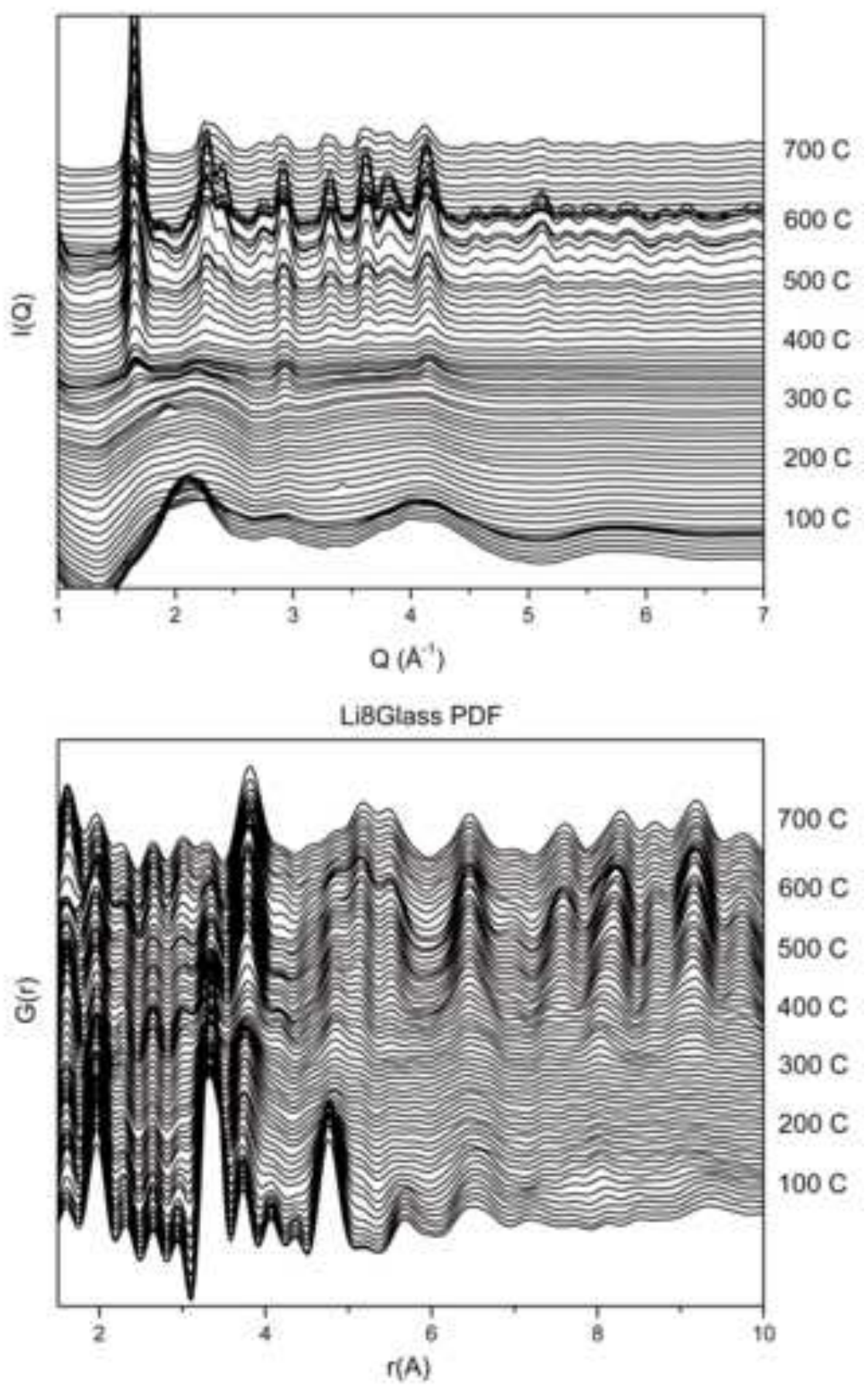
Figure 7

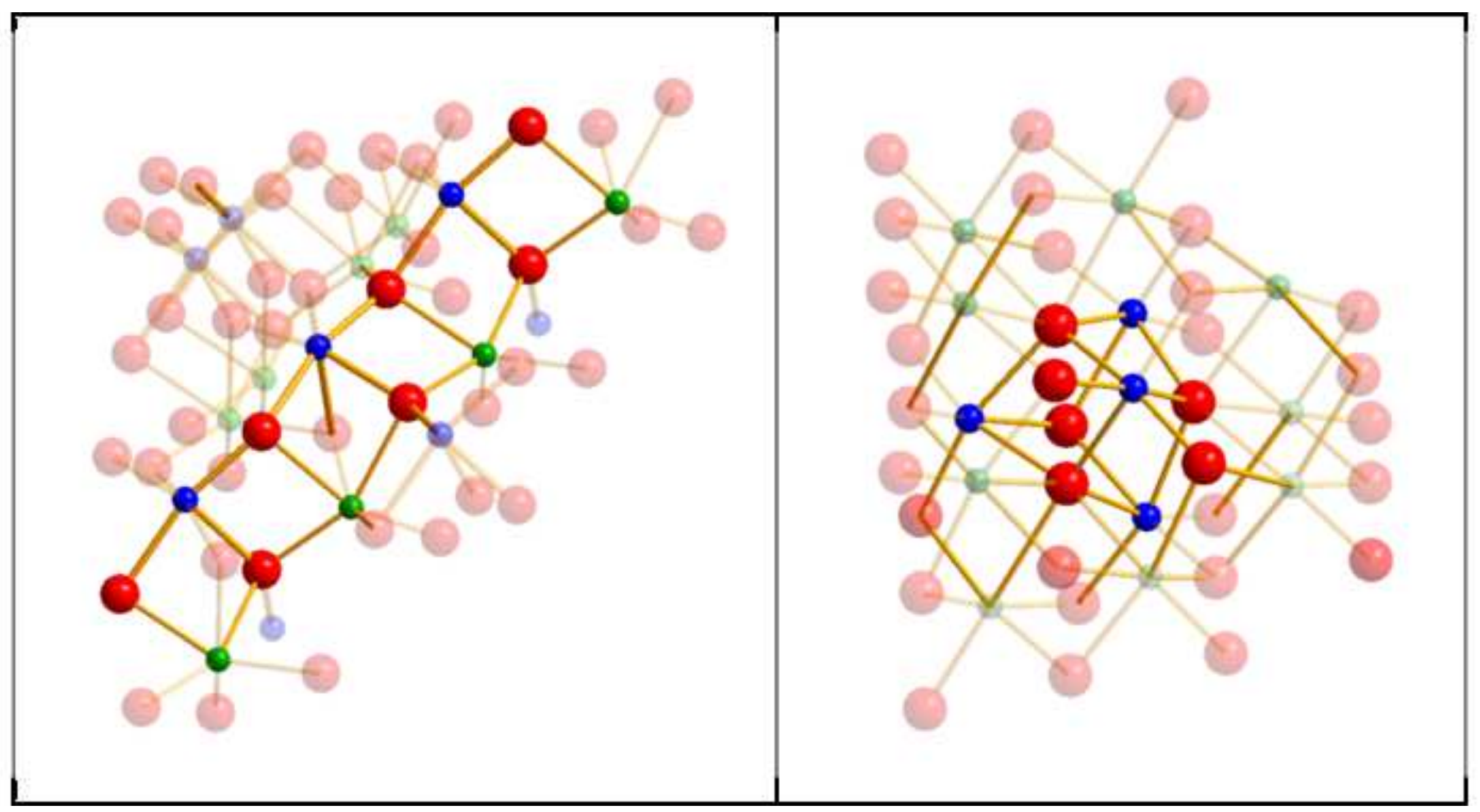




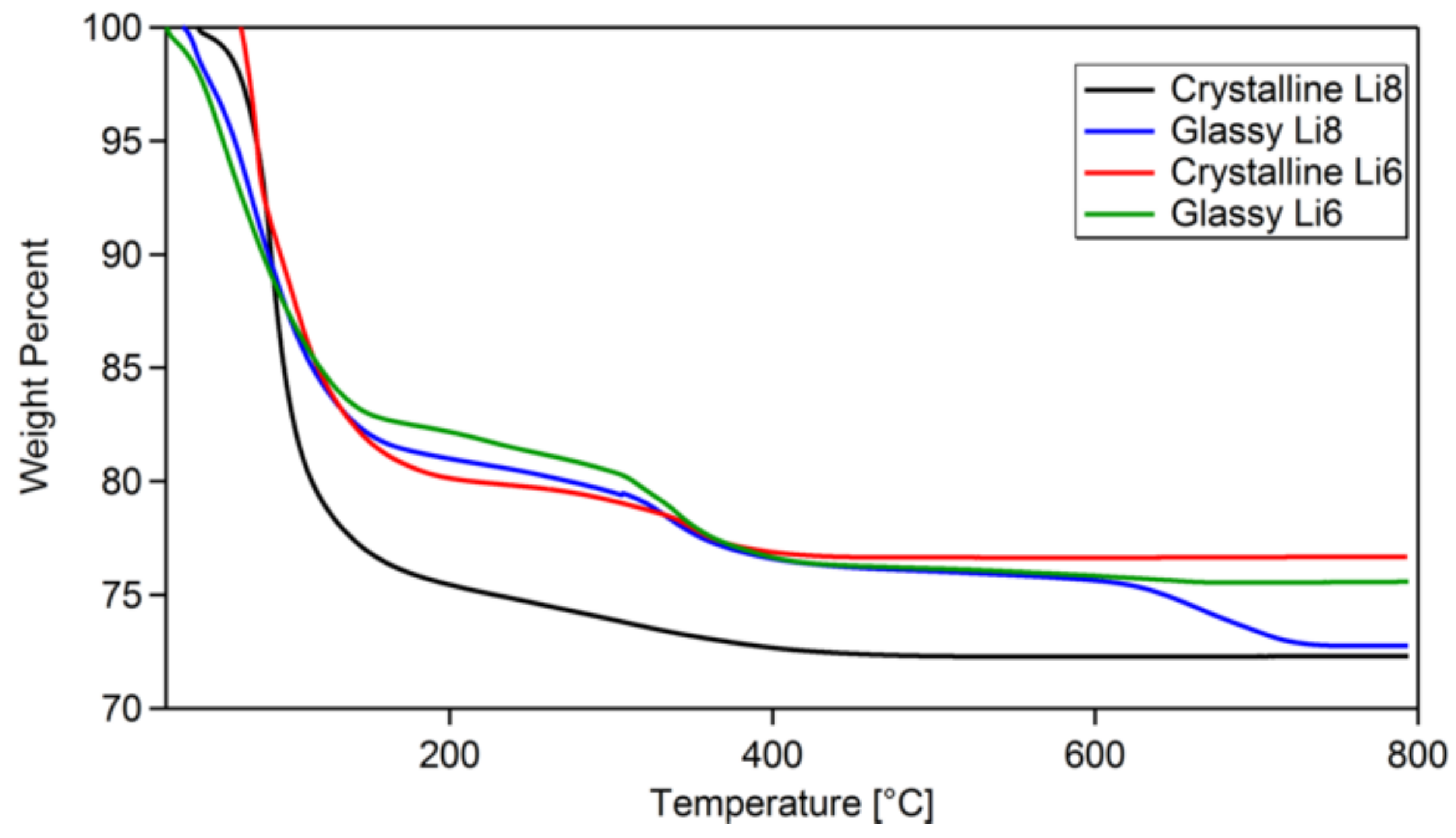


Figure 9

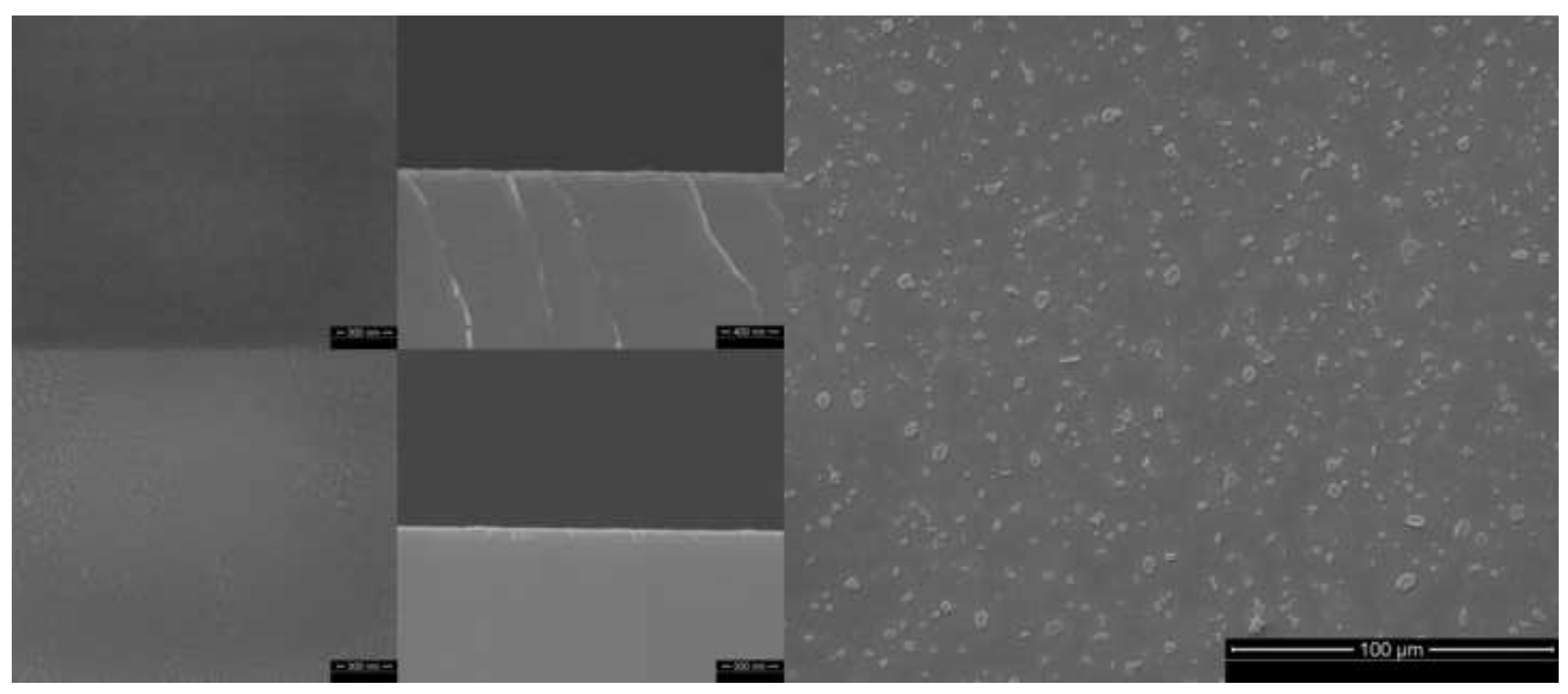




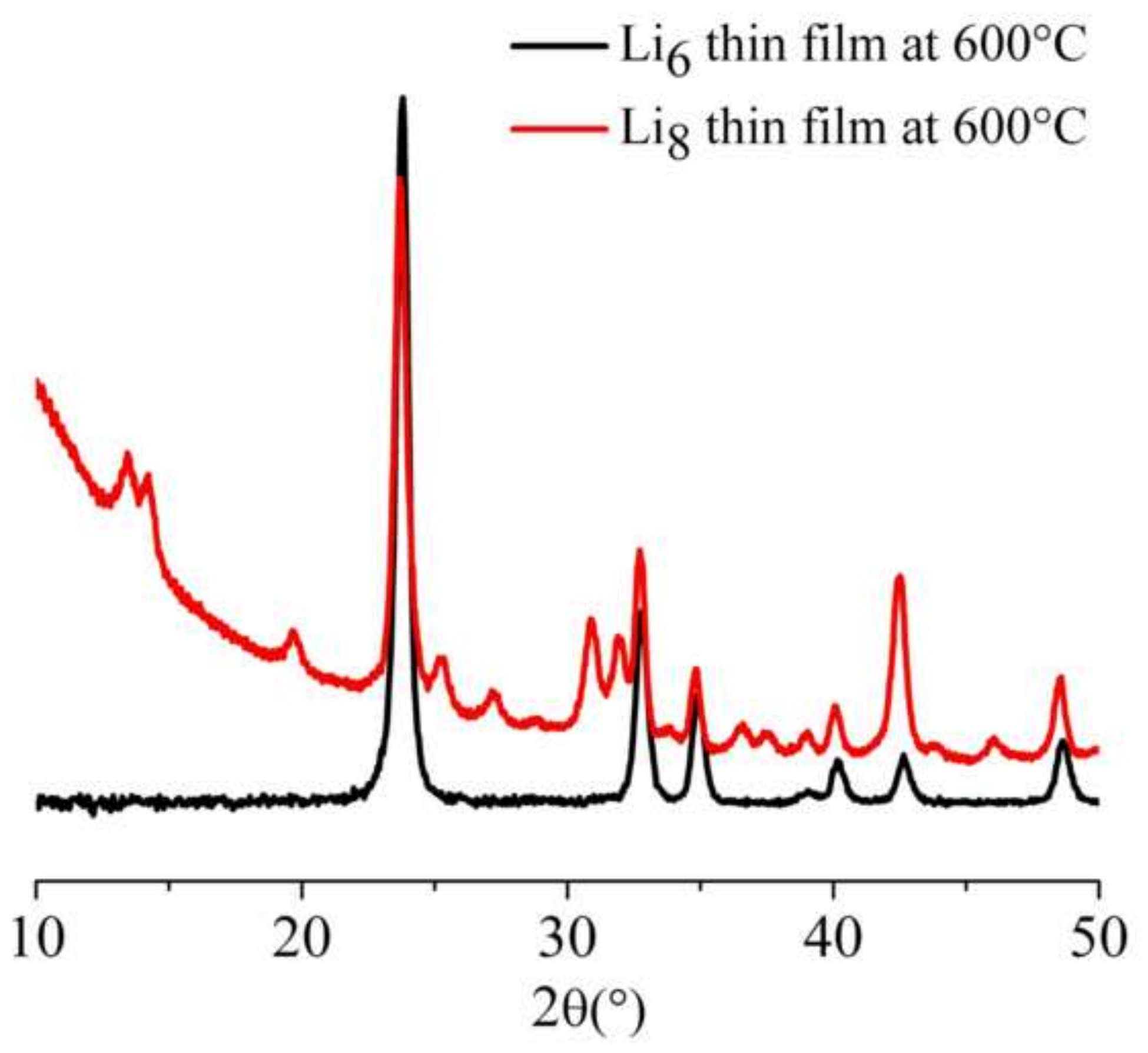




\section{Figure Captions}

Figure 1. Schematic showing stepwise transformation from precursor cluster solid (a) to final thin film product (f). Intermediate states are: dissolved precursor cluster (b), solution dropped onto substrate (c), rapid dehydration via spinning (d), further dehydration and condensation via low temperature heating (e) and formation of metal oxide phase via annealing (f).

Figure 2. Views of Li8. 2a (left) shows two $\left[\mathrm{Nb}_{6} \mathrm{O}_{19}\right]^{8-}$ Lindqvist ions plus the Li-water adamantoid cluster. $2 b$ (right) shows the arrangement of $\mathrm{Li}^{+}$and water only on the lattice. Blue octahedra are $\mathrm{NbO}_{6}$, green spheres are $\mathrm{Li}$, red spheres are $\mathrm{O}$, black spheres are $\mathrm{H}$.

Figure 3. $\log$ (intensity)- $\log (\mathrm{q})$ SAXS scattering curves for Li6 (top) and Li8 (bottom) solutions of variable concentration. The dotted black lines are curve fits that include structural parameters (Li6) or simultaneous fit of two phases (Li8).

Figure 4. PDDF analysis of Li6 solution SAXS data. Inset: showing dimerization of the diprotonated $\left[\mathrm{H}_{2} \mathrm{Nb}_{6} \mathrm{O}_{19}\right]^{6-}$ (see text). The black arrow shows the short dimension and green arrow shows the long dimension of a dimeric specie.

Figure 5. Left: Experimental (room temperature) PDF data along with a simulated PDF pattern of for both the monomer and dimer. Right: representation of two associated diprotonated Lindqvist ions, $\left[\mathrm{H}_{2} \mathrm{Nb}_{6} \mathrm{O}_{19}\right]^{6-}$ plus an associated water molecule to illustrate peak assignments of the PDF (see accompanying Table 2).

Figure 6. S(Q) (top) and G(r) (bottom) of glassy Li6 (left) and glassy Li8 (right) with in-situ heating.

Figure 7. Left: view of $\mathrm{LiNbO}_{3}$ emphasizing alternating edge-sharing $\mathrm{Li}$ and $\mathrm{Nb}$-centered octahedra. Right: view of ordered $\mathrm{Li}_{3} \mathrm{NbO}_{4}$ emphasizing tetranuclear core of edge-sharing $\mathrm{Nb}$ octahedra. Blue is $\mathrm{Nb}$, green is $\mathrm{Li}$ and red is $\mathrm{O}$.

Figure 8. Thermogravimetric analysis of Li6 and Li8 materials

Figure 9.(a) SEM images for surface and cross section views of films deposited from aqueous Li6 after drying at $80^{\circ} \mathrm{C}$ for $3 \mathrm{~min}$ then annealing at $600{ }^{\circ} \mathrm{C}$ for $30 \mathrm{~min}$. (b) SEM image of thin film deposited from Li8, reflecting the morphology of the precursor salt.

Figure 10. X-ray diffraction spectra of thin films deposited from Li6 and Li8 and annealed at $600{ }^{\circ} \mathrm{C}$. The film from Li8 shows a mixture of $\mathrm{Li}_{3} \mathrm{NbO}_{4}$ and $\mathrm{LiNbO}_{3}$, reflecting the $\mathrm{Li}: \mathrm{Nb}$ ratio, while the film depositing from Li6 is pure phase $\mathrm{LiNbO}_{3}$. 

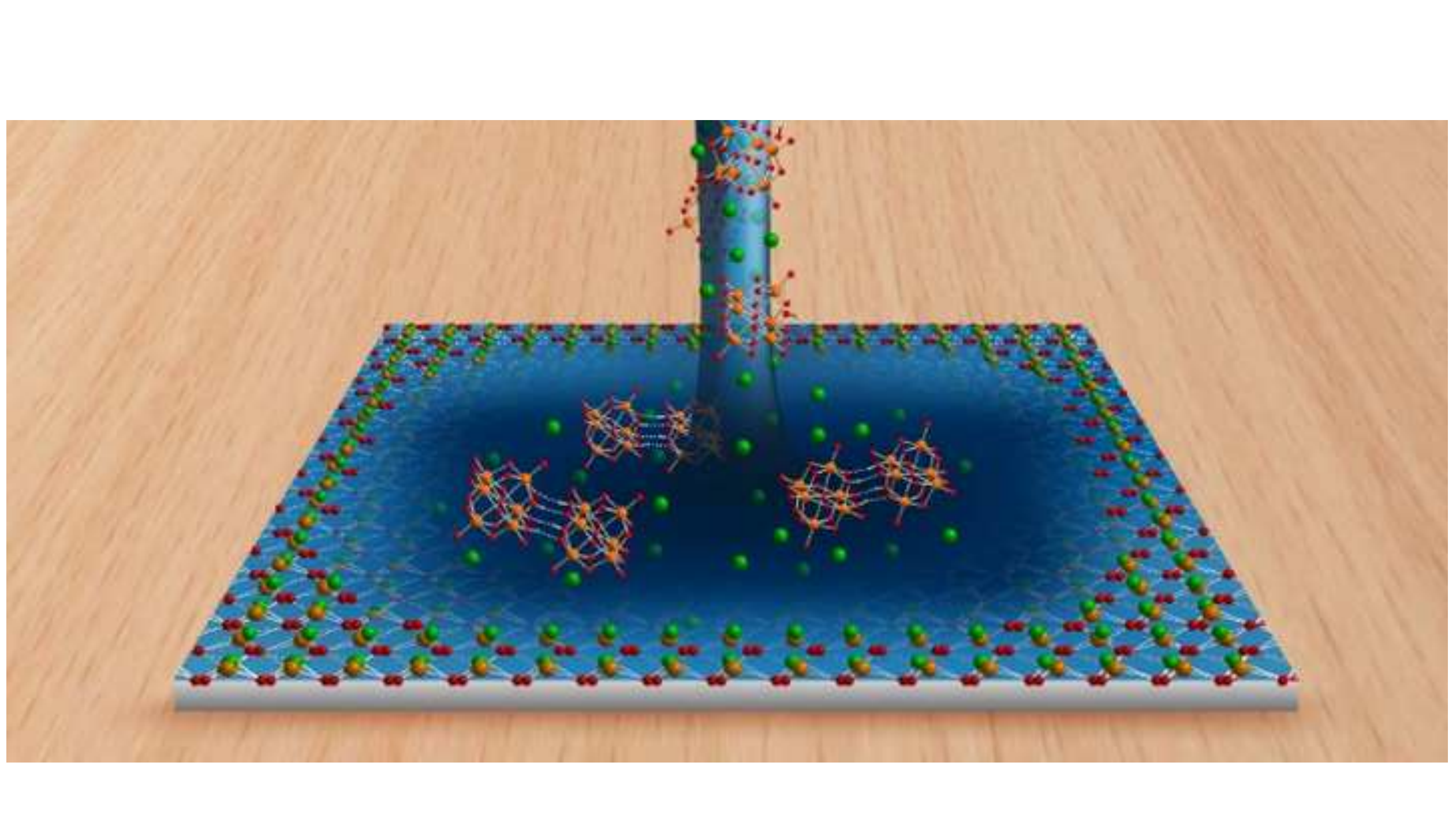

.
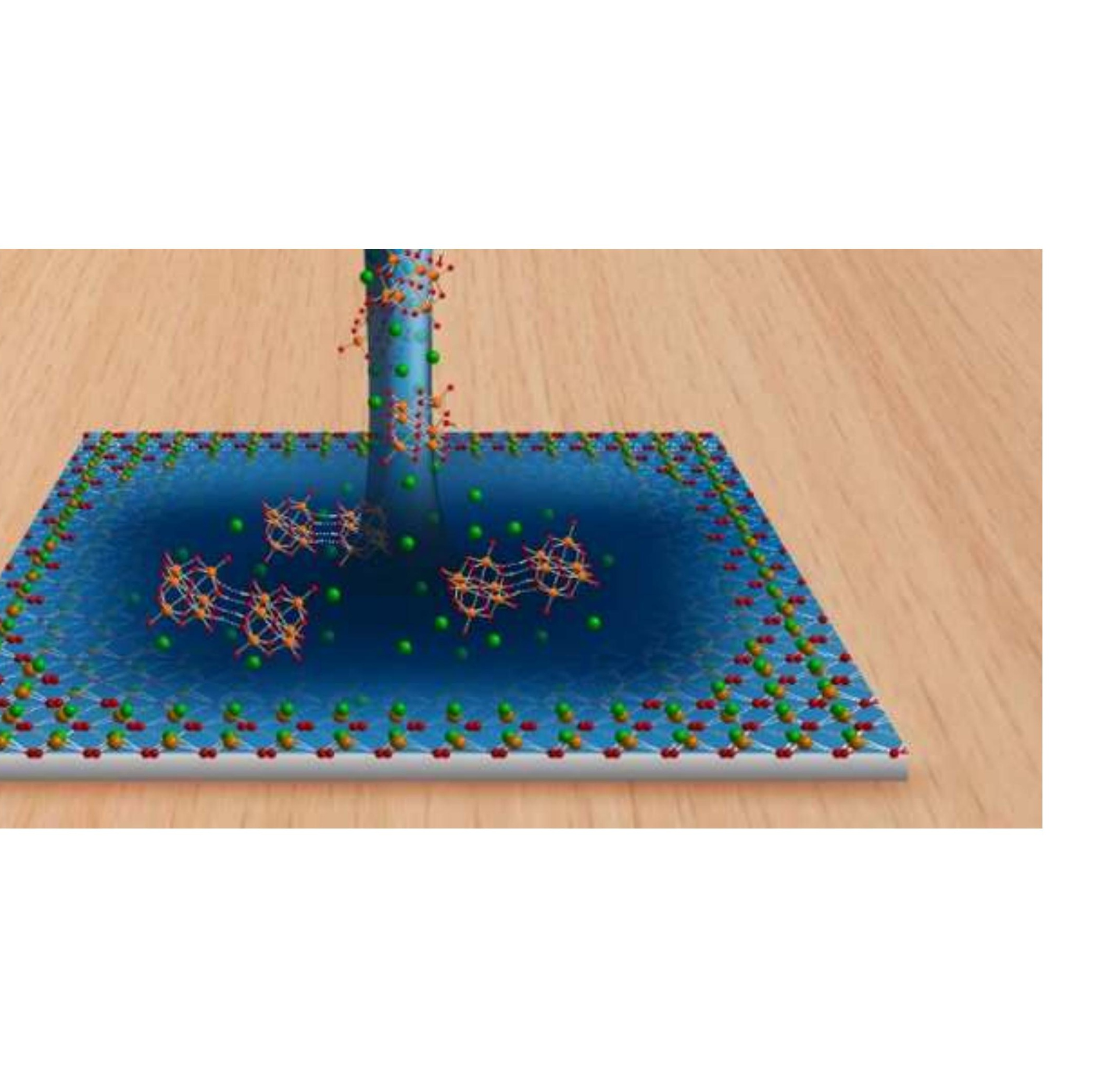
Graphical Legend

Aqueous lithium polyoxoniobate salts were used to prepare lithium niobate $\left(\mathrm{LiNbO}_{3}\right)$ thin films. Fundamental studies were performed to investigate the interactions in the transition from precursor cluster to the oxide film. It was found that acid-base and ion-association chemistries of the aqueous and gel systems significantly affect the key processes in this atom-level journey. 